\title{
Slowing Down and Digging Deep: Teaching Students to Examine Interview Interaction in Depth
}

\author{
Brigette A. Herron and Kathryn Roulston
}

\begin{abstract}
Teaching students to become critical consumers of interviews, which often serve as influential sources for learning and interpreting world events, is important in today's information-rich world. This paper outlines an approach to teaching in-depth interviewing in which students examine excerpts from interviews (e.g., archival collections, oral histories, or media interviews) using the tools of ethnomethodology and conversation analysis to "slow down" and "dig deep" into the social aspects of interviews. Using two case examples from undergraduate and graduate classrooms, we illustrate how this approach helps students to notice how question-answer sequences unfold and encourages critical consumption and participation in interviews.
\end{abstract}

\section{Background}

At some point in our lives, we are likely to find ourselves participating in an interview. Broadly speaking, interviews are seemingly mundane social interactions where people ask and answer questions for a particular purpose. In their many forms-from media interviews, celebrity interviews, job interviews, medical interviews, to forensic interviews-interviews are ubiquitous social interactions we often take for granted to help us access information we need. Undergraduate and graduate students alike will encounter multiple opportunities to observe and participate in interviews in order to learn or share important information. Regardless of a student's particular field, area of interest, or career goals, recognizing the social actions at play in various interviews is a valuable part of professional development and an important life skill.

We often do not take the time to notice what is going on in interviews. By slowing down and engaging in repeated viewing of interviews in a systematic way-we suggest using the tools of ethnomethodology and conversation analysis - students can begin to think critically about the way questions are posed and answered to communicate specific meanings, represent particular identities, and influence what can be discussed next. By systematically examining what goes on in interviews, students can strive to make intentional decisions about how they ask and answer questions, and what information they derive from interviews available through various media sources.

Some scholars have argued that interviews have become so ubiquitous we actually live in an Interview Society (Atkinson \& Silverman, 1997; Gubrium \& Holstein, 2002). Yet the proliferation of interviews as a primary source for both knowledge and entertainment obscures the intricacies of interactions and the challenges of conducting a "good" interview. Surprised by what happens in interviews, novice 
interviewers often struggle with artfully asking questions of research participants (Roulston, deMarrais, \& Lewis, 2003). Scholars have described a variety of approaches to teaching research interviewing. For example, Hsiung (2016) described how archived interviews could be used to introduce students to interviews. Literature on teaching qualitative interviewing focuses on practice in class, assignments, or authentic projects (e.g., Charmaz, 1991; Chenail, 2011; Jacob \& Furgerson, 2012; Wellin, 2007), and reflection on practice (Hsiung, 2008; Uhrenfeldt et al., 2007; Roulston et al., 2008), or some combination of the two (Lippke \& Tanggaard, 2014; Sattin-Bajaj, 2018). In order for students to learn how to interview effectively, scholars have written on multiple aspects of the research process, including:

- developing reflexive awareness and the skill of critical observation;

- learning how to listen;

- learning how to design research studies, conduct interviews, and practicing those skills; and,

- learning how to interpret and analyze interview data (Roulston, 2012).

This article examines the development of critical observational skills. We do this through the act of slowing down and digging deep in examinations of interview interactions with the tools of ethnomethodology (EM) and conversation analysis (CA). Concerning the idea of the philosophy of slowness, Ulmer (2017) has suggested possibilities for scholars to find slower ways of scholarly being, through writing a Slow Ontology, or "a state of being in which scholars chose to live writing and research through locality, materiality, and artisanal craft," (p. 201). We are inspired by the concept of Slow Ontology, which explores alternatives to hurried, mechanical assembly-line writing. We see the examination of interview practice as another locality where students may be encouraged to slow their way of scholarly being, using specific tools that encourage an in-depth look at interview interactions to nurture critical observation skills.

Our pedagogical approach is grounded in the scholarship of teaching interviewing, particularly strands encouraging student reflection on interviews, whether their own interviews or those conducted by others (Roulston, 2012). We ground our approach in a constructivist view of teaching and learning, which focuses on being learner-centered, designing learning encounters that are active and contextualized, and de-stigmatizing mistakes (Shah, 2019). This aligns with approaches to adult learning that emphasize fostering critical reflection with adult learners (Mezirow, 2000). Elsewhere, we have written about our approach to fostering critical reflection on interviewing by teaching with media interviews and other sources from cinematic society (Roulston \& Herron, in press).

We explore two examples of an initial activity for undergraduate and graduate coursework to orient students to the complexities of asking and answering questions in open-ended interviews. The classes where we used this approach were both interdisciplinary-one a first-year seminar on The Art of Interviewing, and the other a graduate course on research interviewing. Although we focus on undergraduate and graduate contexts, we believe these teaching strategies and the pedagogy of slowing down and digging deep can also be used with various learners including high school students and adult learners in general. This requires a creative and inclusive approach by educators to address diverse learning needs and can be accomplished by carefully choosing interviews or interviewing practice 
assignments that are appropriate for specific teaching and learning environments. We argue that using the tools of EM and CA in teaching can help students notice and make choices about how to conduct interviews, participate in interviews, and interpret interviews in scholarly and critically minded ways. We first define what we mean by EM and CA, before describing the methods we used to inform our pedagogical approach.

\section{Ethnomethodology}

Ethnomethodology is an approach to research developed by the sociologist, Harold Garfinkel (19172011). Garfinkel's early work examined the organization of the everyday-how people ("members") make sense of one another to accomplish social actions, or what he termed "members' methods." Garfinkel used unorthodox approaches to examine how people make sense of one another (Garfinkel, 1967), encouraging his students to engage in breaching experiments to bring the "seen but unnoticed" background features in everyday encounters into visibility (p. 36). For example, he prompted his students to see what happened when they genuinely responded to the question "How are you?" (which contradicts the norm in Western society to typically treat such questions as "greetings," rather than literally). His students' written examples of what followed indicated that interactions were marked by conflict and problems when people departed from social norms.

In this article, we draw on EM to outline an approach to teaching qualitative research that helps students to bring to the fore what is "seen but unnoticed" about interview practice. By keenly observing others' interview practices as an initial activity, we argue that students will begin to develop the skills to examine their own interviews (Roulston, 2016).

\section{Conversation Analysis}

Harvey Sacks (1935-1975) met Garfinkel at Harvard University when the latter was on sabbatical from University of California, Los Angeles. Sacks went on to complete his PhD in Sociology at the University of California, Berkeley in the early 1960s, and remained in touch with Garfinkel. When Garfinkel and Sacks began looking at tape-recorded telephone calls from the Center for the Scientific Study of Suicide where Sacks served as a fellow (Sacks, 1995, Introduction, xiii-xv), they were both surprised at the "degree of order exhibited" (Garfinkel, 2006, p. 11) in the talk. Sacks began to focus explicitly on the social organization of talk.

Sacks went on to describe the basic principles of turn-taking with his colleagues, Emanuel Schegloff and Gail Jefferson (Sacks et al., 1974), along with phenomena such as "repair," "recipient design," and "preference structure" —all basic concepts used in CA. Since that time, the field of CA has grown, with practitioners working all over the world in diverse fields. Researchers typically provide detailed transcriptions of talk-in-interaction, including pauses, overlapping utterances, and other features of talk (e.g., speed of talk) using conventions first developed by Gail Jefferson (Atkinson \& Heritage, 1999). Using tools from CA, researchers have examined diverse topics, including medical interaction (Heritage \& Maynard, 2006), and in workplace contexts (Drew \& Heritage, 1992), among others. 


\section{Using EM and CA to Examine Interviews}

For over 35 years scholars have used EM and CA to examine the construction of interviews, including news interviews (Clayman \& Heritage, 2002), standardized survey interviews (Houtkoop-Steenstra, 2000; Maynard et al., 2002; Suchman \& Jordan, 1990), and qualitative interviews (Baker, 1983; Hester \& Francis, 1994; Roulston, 2006, 2019). The argument for using EM and CA to examine interview talk rests on the idea that interviews are organized social activities that take place as part of everyday life. This is equally true whether the purpose is generating data for research, spectacle for entertainment, or fact-based information for news reports. From an EM perspective, there is no "time out" from the lived experience of making sense of others' actions and utterances. For these reasons, educators may find using the tools of EM and CA useful in teaching their students, at various levels and across disciplines, to examine interview talk.

\section{Organization of Paper}

The strategies we discuss enable students to become more aware of how interaction is accomplished to inform their own practices as interviewers, and help them critically interrogate interviews they encounter. Using two examples, we draw on the tools of EM and CA to help students examine interview talk systematically, where they can "slow down" and "dig deep." The selection of the types of interviews used for these classroom activities serves as a place for educators to connect with students in meaningful and authentic ways, for instance by selecting topical media interviews, or by allowing students to participate in the selection of interviews examined.

We begin with an example from an introductory level course with undergraduate students. This provides an example of how interviews featuring controversial or timely topics can be used with students and how educators can use the tools of EM and CA to support deep thinking about asking and answering questions without having to explain the intricacies of EM or CA to students. Next, we increase the complexity of utilizing EM and CA in a subsequent case with graduate students, who were encouraged to engage in complex reflections on interview practice.

\section{Case 1: Asking and Answering Questions About Controversial Topics}

As educators working with an interdisciplinary group of undergraduate students, we wondered if students could be encouraged to examine interview interaction without having explicit knowledge of EM and CA. Thus, as an initial activity in a first-year undergraduate class, The Art of Interviewing, we selected an interview with Martin Luther King Jr. conducted on November 2, 1967, by Mike Douglas and Tony Martin on the Mike Douglas Show - a televised daytime talk show. In this example, we were working with undergraduate students in the southern United States who were very familiar with the legacy of Martin Luther King Jr. as an icon of the Civil Rights movement. We selected this clip to align with the upcoming MLK Jr. Day of service, in which students were encouraged to spend the day volunteering and serving the community in some way. This connected the interview activity to the students' lives in an 
authentic way. In this interview excerpt, the interviewer (Douglas) and another guest (Martin) confront King on his views on the war in Vietnam, and his standing amongst the African-American community. Rather than providing a transcription of the talk, we relied on students' repeated viewings of the video clips (see Appendix 1 for URLs and further interview details).

After repeated viewings, we asked students to select and write down several of the questions posed as part of a reflection paper. Students were not required to use CA transcription conventions but were asked to critically examine how questions were posed and how King oriented to these questions. There is precedent in the literature for using an ethnomethodological approach to examine talk in police interrogations in which the talk is not transcribed in detail (David et al., 2018). The power of these scholars' analysis of police interrogations lies in their focus on how interrogations are handled by speakers, and what the implications are for the parties present. In this case, we encouraged students to consider how speakers co-constructed the King interview by looking at the same sorts of interactional details noted in Case 2. The focus of this assignment was to have students critically analyze the questions posed (what in CA parlance is the first-pair part of an adjacency pair), and then what happens next (the answer, or second-pair part of an adjacency pair) (Sacks, 1995).

After viewing the first excerpt in class, we modelled how one might critically examine how questions are asked and answered. Following this in-class demonstration, students were assigned the following homework prompt:

Watch the other two sections of the MLK Jr. interview from class and write out the questions posed. Next, write a two-page, double-spaced reflection paper about your impressions of the remaining two sections of the $M L K J r$. interview (2/3 \& 3/3) that focuses on:

1) What are the questions posed to MLK Jr. in the interview?

2) How does MLK Jr. orient to and take up these questions?

3) How does the interviewer follow up?

\section{Student Responses to the Activity}

We found that students capably analyzed both the interviewers' and interviewee's actions. Below, with students' permission, we include some of their responses, which demonstrated their ability to observe the adversarial moments that occurred in interaction and how these were downgraded. Specifically, students commented on:

1. The changing tone across the interview interaction and how that was accomplished by speakers.

2. How interruptions on the part of the interviewers contributed to aggressive lines of questioning.

3. How King's orientation to aggressive questions worked to downgrade tension and forward interaction.

4. How King repeatedly declined to offer defensive responses to questions, thereby demonstrating his exceptional oratory skills in pursuing nonviolent interactions.

These excerpts from students' reflections illustrate the kinds of observations that were generally made across the class. 


\section{Changing Tone Across the Interview}

The first excerpt features a student's description of how King artfully manages a critical question about his relationship with President Johnson in a way that avoids responding to the question and changes the tone of the interaction.

On another occasion, the interviewer cites Dr. King's relationship with President Johnson, asking whether or not their relations have fluctuated in light of Dr. King's remarks. King chuckles, lightening the solemn tone of the interview and creating a more casual environment. He also somewhat avoids the question, taking attention away from himself and turning it towards President Johnson with his response, "Well, I guess the president would have to answer that question".

Another student commented on King's ability to influence the overall tone of the interview in a way that was lighthearted, and dispelled tension.

\section{How Interruptions Work in Interviews}

The following student excerpt provides a clear description of how King deflects interruptions that challenge his standing within the Civil Rights community by continuing his line of thought and agreeing with the assumption in the question posed by the interviewer.

When asked about Dr. King's thoughts of militant leaders taking over his movement, his responses were interrupted with questions about the approaches of Stokely Carmichael and $\mathrm{H}$. R. Brown [activists in the Student Nonviolent Coordinating Committee (SNCC) in the 1960s]. King said he disagrees with their views philosophically before being interrupted again with, "Do you have disagreements with them?" King said, "Definitely, I know them both very well-" and was interrupted asking, "Do they agree with you?" Dr. King ignores this and goes on to explain that both Carmichael and Brown are in on the movement and probably disagree with him quite a lot.

\section{How King Orients to Aggressive Lines of Questioning}

In the next excerpt, another student provided an analysis of how Douglas posed a question directly confronting King. The description notes the pivot in the interview interaction in which King disagrees with the interviewer's quoted assertion about his own standing that discredits King's efforts.

During his interview with Mike Douglas and Tony D. Martin, Martin Luther King Jr. is frequently on the defense concerning his actions involved with the African-American community and the implications of these actions during the Civil Rights Movement... Whereas earlier in his interview Dr. King remains relatively impartial in his defenses and avoids both agreeing and disagreeing, a switch occurs in his response to this question. He immediately states, "I'm sorry to disagree, [but] I stand with my original statement that people who have been alienated as a result of standing against the war have been alienated anyways." 
Here, the student observed the way King avoided defending himself from the outside critique packaged by the interviewer, instead using his response to reiterate an earlier assertion, and reframe the direction and his approach to answering questions in the interview.

\section{King's Use of Excellent Oratory Skills to Manage Interview Talk}

In the final example, we include a student excerpt describing King's management of the overall interview interaction where he is asked difficult questions and interrupted by the interviewers.

Although some of the questions posed to Dr. King were very difficult to answer with grace, and despite several interruptions, he managed to answer more powerfully than one could imagine. Many of the comments and questions given by Douglas and Martin had an attacking tone and felt as though they were trying to corner Dr. King. He had to disagree with many of their comments, but his excellent oratory skills and powerful views never waver. Another fault of the interviewers in my opinion is the repeated interruptions of Dr. King. I believe that if you are asking someone a question, you should wait and give them respect until they have finished answering that question. Dr. King did an excellent job orienting to the difficult questions and using both statistics and quotes to strengthen his thoughts and arguments.

Notable in this reflection is the student's critical analysis of how the interaction was a collaborative production and the application of her observations to evaluate the interview practices. This activity could be expanded by having students write about what they have learned about good interview practice, and how this might affect their future conduct as both interviewers and interviewees.

In the next section, we discuss our experiences having students work with a detailed transcript of a media interview featuring a difficult interaction between the interviewee and interviewer.

\section{Case 2: Examining Difficult Interactions}

In this case we examine the use of a publicly available media interview in a graduate-level qualitative research class focused on interviewing. We wanted students to gain experience examining more detailed transcriptions than are typically used by many researchers (e.g., pauses, overlaps are included, along with comparative volume and speed of talk), and reflect and relate this exercise to their own interview practice. By having students work systematically through a transcript we provided, we alerted them to possibilities occurring in their own interviews worth a "second look" (Baker, 1983). We selected a well-known interview of film director, Quentin Tarantino, conducted by journalist Krishnan Guru-Murthy of Channel 4 in the UK, where, shortly into the interview, Tarantino refuses to follow Guru-Murthy's line of questioning. The excerpt demonstrates how the formulation of interview questions is crucial for considering what comes next, and how the interviewer and interviewee might pursue different agendas. This excerpt shows Tarantino promoting his latest movie, and Guru-Murthy claiming to pursue a "serious" line of questioning, while simultaneously instigating a "difficult interaction."

We began the session having students reflect on their own interview practice (Appendix 2). After discussion of students' reflections, we examined the example of a "difficult interaction" exhibited in 
Tarantino's interview. Students were guided through an analytic process outlined by Pomerantz and Fehr (1997), where they were asked to identify various features of talk that occur in the interview using the transcript we generated and provided for students. The full sequence for analysis involves the following steps:

1. Select a sequence.

2. Characterize the actions in the sequence.

3. Consider how the speakers' packaging of actions, including their selection of reference terms, allows certain understandings of the actions performed and the matters talked about. Consider the recipients' options that are set up by that packaging.

4. Consider how timing and turn-taking allows for certain understandings of the actions and the matters talked about.

5. Consider how the ways the actions were accomplished implicate certain identities, roles and/or relationships for those involved (Pomerantz \& Fehr, 1997).

We selected this sequence (Step \#1) because it provided a provocative example of what can happen when problematic interactions transpire. Later, students could examine interactions from their own interviews. With basic definitions of various conversational objects and resources, students began by characterizing utterances in the transcript under the following headings (Step \#2).

- Questions

- Answers

- Formulations (in which a speaker sums up what was said in a way that deletes information, adds something, and transforms a prior utterance) (Heritage \& Watson, 1979).

- Accusations

- Agreements/Disagreements

- Repairs (clarifying or restating what was said in a way that sorts out misunderstandings)

- Delays

The following excerpt is an example from the longer transcription (which is available from the authors; the URL for the interview is found in Appendix 3).

Excerpt 1.

46. IR =but why are you so sure that there's no link between

47. enjoying movie violence and enjoying real violence

48. IE I don't I well I'm n-gonna tell you why I'm so

49. sure don't ask me a question like $>$ that I'm not gonna<

50. I'm not biting (.) I refuse your question=

51. IR = $\quad$ \$ $\$$ why?

52. IE >because I refuse your question I'm not your slave

53. and you're not my master $<$

54. IR IJU- 
55. IE you can't make me dance to your tune [I'm not a ]

56.

[l can't make]

57. [monkey]

58. IR [you \$I] can't make you answer anything \$ I'm just I'm

59. asking you interesting questions=

60. IE =and I'm saying I'm saying I refuse

In line 46, the interviewer pursues a response from Tarantino regarding his view on the link between film violence and actual violence (this interview was conducted soon after the school shooting at Sandy Hook Elementary School in the U.S. in December 2012). At lines 48-50, Tarantino refuses to respond to the question. Again, the interviewer pursues a response-this time asking for a rationale for the refusal to respond. Here, Tarantino provides a response, with noticeably faster talk. At line 54, the interviewer begins a response, but lines 55-58 show overlapping talk, as Tarantino abruptly interrupts the interviewer's utterance. This short excerpt shows how responses to questions do not always answer the questions posed, as well as illustrating an accusation and denial. The disagreement evident in this excerpt is marked by several interruptions.

Students then examined how the talk is "packaged" (Step \#3) and how this contributes to the trajectory of talk using the following headings.

- Louder talk/Softer talk

- Extreme case formulations in which speakers use "extreme" words such as "never," "always" and so forth as a way to legitimize claims (Pomerantz, 1986)

- Faster/slower talk

- Downgrades/upgrades (in which speakers present a revised version of what has already been said in ways "downgrading" or "upgrading" claims)

The following excerpt provided an example of the text students used to examine the packaging of the talk.

Excerpt 2.

89. IE I-I IT'S NOT MY JOB to flesh it out

90. IR $\quad$ >no it's my job my job to try and ask you [to that's $<$

91. IE [and I'M

92. SHUTTING YOUR BUTT DOWN [heh hehhehheh

93. IR all [and that's entirely that's

94. entirely your your right

95. IE this is a commercial for my movie 
In Excerpt 2, we see louder talk, as Tarantino asserts his right not to respond to the interviewer's questions. Here, the interviewer responds with agreement and an extreme case formulation ("entirely"). However, we see a difference in agendas — with the interviewer pursuing what he later asserts at line 206 are "serious themes," while Tarantino claims the interview is a "commercial" for his movie, Django Unchained.

As noticeable in Excerpts 1 and 2, students located points in the talk in which timing and turn-taking were made visible via the close transcription of talk (Step \#4), using the following headings.

- Overlapping talk

- Silences

Finally, students were encouraged to consider the membership categories (Baker, 2002) employed by speakers, and the implications for the identities produced by speakers (Step \#5). Students observed how Guru-Murthy produced the identity of a serious interviewer, while Tarantino performed the identity of a producer promoting his movie. By identifying the membership categories and identities in interview talk, students began questioning the multiple purposes that interviews serve and readily identified the conflicts resulting from different interviewing agendas. Through this examination, students gained preparation to look more closely at their own interview practice. This is useful for examining motivations underlying research interviews and the power dynamics involved in interview interaction. Student reflection on the ethical implications of interview interactions were further encouraged by having students write responses to a series of reflection questions (see Appendix 4). A detailed example of considering membership categories employed and identities produced by speakers is found in Herron (2019).

This is an introductory-level activity to prompt students to examine how interview interactions rely on collaborative achievement in order to generate research data. In particular, difficult interactions in interviews are good places to encourage students to "slow down" and "dig deep" as they provide a clear, interesting, and informative entry point. In our experience, we have observed students actively engage in this activity, and readily identify what goes on in the talk. This activity may serve as a useful scaffolding activity to get students to reflect on interviews as conversational interactions that serve more purposes than simply the generation of information.

\section{Discussion and Conclusions}

In Case 1, we provided an approach to working with students that does not explicitly use EM or CA, but encourages students to analyze interview interactions critically while considering various interactional and interpersonal issues that arise. In Case 2, we illustrated how we used a transcript of difficult interactions from a media interview, using methods drawn from CA as a way to examine the kinds of social actions that can occur in interviews. This encourages students to reexamine their own interviews with a view to understanding unexpected interactions and surprises. When students view a news interview with a politician or world leader, we hope they take the time to think about how the questions asked set the tone for the answers that follow. We hope they slow down to question the motivations and 
intended messages that are communicated, with an eye toward examining the actions accomplished when people ask and answer questions.

Threaded throughout these cases are moments where students are invited to reflect further on implications for their own interview practice and participation-whether for the purpose of conducting and participating in any number of interview types (i.e., job interviews, journalistic interviews, oral history interviews, clinical interviews, and research interviews). For example, how might students be encouraged to deeply reflect on the kinds of actions that go on in interviews, such as the use of interruptions to pursue an agenda, in Case 1? How can novice researchers be encouraged to consider the ethics of their pursuit of an interview agenda which is not aligned to that of the interviewee, as in Case 2?

We encourage educators to use these strategies as a starting point for getting students to slow down and dig deep into interviews, and to use their own creativity to expand and develop these tools in ways that serve the needs of their particular student populations. For instance, educators might choose to select interviews that will resonate with issues that are important to their students or have the students themselves select interviews. Through consideration of the variety of interview styles and actions disseminated in contemporary society, we hope educators can draw from these strategies using EM and CA to encourage students to critically analyze the information derived from interviews they view, along with those they participate in as interviewers and interviewees.

\section{Acknowledgments}

The authors would like to thank Jesse Baynes, Kayla Muench, Avery Pingpank, and Amanda Sarkady for graciously allowing us to use their written class reflection assignments as examples in this paper.

\section{References}

Atkinson, J. M., \& Heritage, J. (1999). Jefferson's transcript notation. In A. Jaworski \& N. Coupland (Eds.), The discourse reader (pp. 158-166). Routledge.

Atkinson, P., \& Silverman, D. (1997). Kundera's immortality: The interview society and the invention of the self. Qualitative Inquiry, 3(3), 304-325.

Baker, C. D. (1983). A 'second look ' at interviews with adolescents. Journal of Youth and Adolescence, 12(6), 501-519.

Baker, C. D. (2002). Ethnomethodological analyses of interviews. In J. F. Gubrium \& J. A. Holstein (Eds.), Handbook of interview research: Context and method (pp. 777-795). Sage.

Charmaz, K. (1991). Translating graduate qualitative methods into undergraduate teaching: Intensive interviewing as a case example. Teaching Sociology, 19(3), 384-395.

Chenail, R. J. (2011). Interviewing the investigator: Strategies for addressing instrumentation and researcher bias concerns in qualitative research. The Qualitative Report, 16(1), 255-262. 
Clayman, S., \& Heritage, J. (2002). The news interview: Journalists and public figures on the air. Cambridge University Press.

David, G. C., Rawls, A. W., \& Trainum, J. (2018). Playing the interrogation game: Rapport, coercion, and confessions in police interrogations. Symbolic Interaction, 41(1), 3-24.

https://doi:10.1002/symb.317

Drew, P., \& Heritage, J. (1992). Talk at work: Interaction in institutional settings. Cambridge University Press.

Garfinkel, H. (1967). Studies in ethnomethodology. Prentice-Hall.

Garfinkel, H. (2006). Seeing sociologically: The routine grounds of social action. Paradigm Publishers.

Gubrium, J. F., \& Holstien, J. A. (2002). From the individual interview to the interview society. In J. F. Gubrium \& J. A. Holstien (Eds.), Handbook of interview research: Context and method (1-32). Sage.

Heritage, J., \& Maynard, D. W. (Eds.). (2006). Communication in medical care: Interaction between primary care physician and patients. Cambridge University Press.

Heritage, J., \& Watson, D. R. (1979). Formulations as conversational objects. In G. Psathas (Ed.), Everyday language: Studies in ethnomethodology (pp. 123-162). Irvington.

Herron, B. A. (2019). On doing 'being feminist' and 'being researcher": Lessons from a novice interviewer. In K. Roulston (Ed.), Interactional studies of qualitative research interviews (pp. 79-101). John Benjamins Publishing Company. https://doi.org/10.1075/z.220.04her

Hester, S., \& Francis, D. (1994). Doing data: The local organization of a sociological interview. British Journal of Sociology, 45(4), 676-695.

Houtkoop-Steenstra, H. (2000). Interaction and the standardized survey interview: The living questions. Cambridge University Press.

Hsiung, P.-C. (2008). Teaching reflexivity in qualitative interviewing. Teaching Sociology, 36(211-226).

Hsiung, P.-C. (2016). Lives \& legacies: A digital courseware for the teaching and learning of qualitative interviewing, Qualitative Inquiry, 22(2), 132-139. https://doi:10.1177/1077800415617205

Jacob, S. A., \& Furgerson, S. P. (2012). Writing interview protocols and conducting interviews: Tips for students new to the field of qualitative research. The Qualitative Report, 17(42), 1-10.

https://nsuworks.nova.edu/tqr/vol17/iss42/3

Lippke, L., \& Tanggaard, L. (2014, 2014/02/01). Leaning in to "muddy" interviews. Qualitative Inquiry, 20(2), 136-143. https://doi.org/10.1177/1077800413510869

Maynard, D. W., Houtkoop-Steenstra, H., van der Zouwen, J., \& Schaeffer, N. C. (Eds.). (2002). Standardization and tacit knowledge: Interaction and practice in the survey interview. John Wiley.

Mezirow, J. (2000). Learning to think like an adult. In J. Mezirow \& Associates (Eds.), Learning as transformation: Critical perspectives on a theory in progress. Jossey-Bass.

Pomerantz, A. (1986). Extreme case formulations: A way of legitimizing claims. Human Studies, 9, 219-229. 
Pomerantz, A., \& Fehr, B. J. (1997). Conversation analysis: An approach to the study of social action as sense making practices. In T. A. van Dijk (Ed.), Discourse as social interaction (pp. 64-91). SAGE.

Roulston, K. (2006). Close encounters of the ' $\mathrm{CA}^{\prime}$ kind: A review of the literature analyzing talk in research interviews. Qualitative Research, 6(4), 535-554.

Roulston, K. (2012). The pedagogy of interviewing. In J. F. Gubrium, J. A. Holstein, A. B. Marvasti, \& K. D. McKinney (Eds.), The SAGE handbook of interview research: The complexity of the craft (2nd ed.) (pp. 61-74). SAGE.

Roulston, K. (2016). Issues involved in methodological analyses of research interviews. Qualitative Research Journal, 16(1), 68-79. https://doi.org/10.1108/QRJ-02-2015-0015

Roulston, K. (2019). Using archival data to examine interview methods: the case of the former slave project. International Journal of Qualitative Methods, 18, 1-13.

https://doi:10.117711609406919867003

Roulston, K., deMarrais, K., \& Lewis, J. (2003). Learning to interview in the social sciences. Qualitative Inquiry, 9(4), 643-668.

Roulston, K., \& Herron, B. A. (in press). Teaching interviewing in qualitative research: Learning from cinematic society. In J. Richards, A. Skukauskaite, \& Chenail, R., Learner-centered, socially constructed, qualitative research: Supporting students as active participants in their own learning. Brill | Sense.

Roulston, K., McClendon, V. J., Thomas, A., Tuff, R., Williams, G., \& Healy, M. (2008). Developing reflective interviewers and reflexive researchers. Reflective Practice, 9(3), 231-243.

Sacks, H. (1995). Lectures on conversation. Blackwell.

Sacks, H., Schegloff, E. A., \& Jefferson, G. (1974). A simplest systematics for the organization of turn-taking for conversation. Language, 50, 696-735.

Sattin-Bajaj, C. (2018). On the same page: A formal process for training multiple interviewers. The Qualitative Report, 23(7), 1688-1701. https://nsuworks.nova.edu/tqr/vol23/iss7/14

Shah, R. K. (2019). Effective constructivist teaching learning in the classroom. Shanlax International Journal of Education, 7(4), 1-13. https://doi.org/10.34293/education.v7i4.600

Suchman, L., \& Jordan, B. (1990). Interactional troubles in face-to-face survey interviews. Journal of the American Statistical Association, 85(409), 232-253.

Uhrenfeldt, L., Paterson, B., \& Hall, E. O. C. (2007). Using videorecording to enhance the development of novice researchers' interviewing skills. International Journal of Qualitative Methods, 6(1), 1-9.

Ulmer, J. B. (2017). Writing slow ontology. Qualitative Inquiry, 23(3), 201-211.

https://doi.org/10.1177/1077800416643994

Wellin, C. (2007). Narrative interviewing: Process and benefits in teaching about aging and the life course. Gerontology \& Geriatrics Education, 28(1), 79-99. 


\section{Appendix 1: Interview Details for Cases 1 \& 2}

\section{Case 1:}

Martin Luther King Jr. on the Mike Douglas Show.

Part 1:

https://www.youtube.com/watch?v=9SfH2uMayks

Part 2:

https://www.youtube.com/watch? $v=$ FQIIE-WIM8\&t=2s

Part 3:

https://www.youtube.com/watch?v=tvB5a9 X/3I

\section{Case 2:}

Interviewer: Krishnan Guru-Murthy

Interviewee: Quentin Tarantino

https://www.channel4.com/news/quentin-tarantino-im-shutting-your-butt-down

\section{Appendix 2: Reflection on Interview Practice}

What was it like for you the first time you transcribed your own talk?

What did you notice about your own conversational mannerisms?

What did you notice about your interviewee's conversational mannerisms?

What aspects of talk were challenging for you to transcribe?

How did you deal with these transcription challenges?

Have you changed your interview practices since that first interview? If so, how? 


\section{Appendix 3: Transcription Conventions}

The following transcription conventions were used in the creation of the transcripts referenced in this paper.

\begin{tabular}{|c|c|}
\hline$?$ & Rising intonation \\
\hline , & $\begin{array}{l}\text { Slightly rising intonation, or incomplete } \\
\text { intonation contour }\end{array}$ \\
\hline$\downarrow$ & Downward fall in intonation \\
\hline$\uparrow$ & Upward rise in intonation \\
\hline$:$ & Elongated syllable or sound \\
\hline CAPITALS & Louder volume than surrounding talk \\
\hline[ & $\begin{array}{l}\text { A single left bracket indicates the point of } \\
\text { overlap onset }\end{array}$ \\
\hline ] & $\begin{array}{l}\text { A single right bracket indicates the point at } \\
\text { which an utterance or utterance part terminates } \\
\text { vis-à-vis another }\end{array}$ \\
\hline$($ ) & Researcher notes about activity \\
\hline$(0.5)$ & Timed pause, half a second \\
\hline$(5.0)$ & Timed pause, 5 seconds \\
\hline (.) & Untimed pause, short, beat \\
\hline Don't & Underline indicates stressed word \\
\hline$=$ & No space between utterances, latching \\
\hline$\circ$ & $\begin{array}{l}\text { Utterance parts bracketed by degree signs are } \\
\text { quieter than surrounding talk }\end{array}$ \\
\hline$<>$ & $\begin{array}{l}\text { Right / left carets bracketing an utterance or } \\
\text { utterance part indicate speeding up }\end{array}$ \\
\hline \# & Creaky Voice/ Vocal Fry \\
\hline
\end{tabular}

Adapted from the following:

Liddicoat, A. J. (2007). An introduction to conversation analysis. Continuum.

ten Have, P. (2007). Doing conversation analysis, a practical guide (2nd ed.). SAGE. 


\section{Appendix 4: Reflection Questions}

- What is this interview about?

- What questions are asked? (write down as many questions as you can)

- How does the interviewer show that they are listening?

- Does the interviewer make additional comments that are not questions? If so, what?

- How would you describe this "interview" (e.g., conversational, confrontational, structured, unstructured)

- What is the context in which this interview is conducted?

- What is the purpose of this interview?

- How successful do you think the interviewer was in achieving his/her purpose?

- In what ways did the questions posed facilitate (or not) an effective interview? 


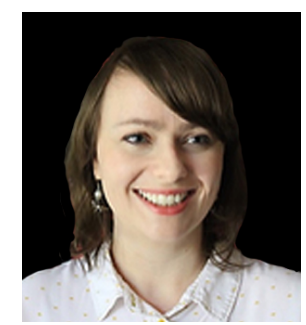

Brigette A. Herron is a research professional at the University of Georgia, in Athens, Georgia, U.S., and holds a PhD in adult education. Her research interests include feminist pedagogy in adult and higher education, qualitative research methods, and examining the influence of philanthropy and dark money on curriculum and pedagogy. She is the co-author of Philanthropy, hidden strategy, and collective resistance: A primer for concerned educators (with K. deMarrais, T. J. Brewer, J. Atkinson, \& J. Lewis, 2019) and has contributed a chapter in Interactional studies of qualitative research interviews (edited by K. Roulston, 2019).

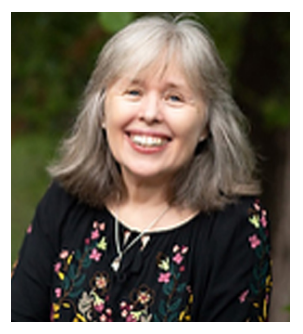

Kathryn Roulston is Professor in the Qualitative Research Program at the University of Georgia in Athens, Georgia, where she teaches qualitative research methods. Her research interests include qualitative research methods, qualitative interviewing, and analyses of talk-in-interaction. She is author of Reflective interviewing: A guide to theory and practice (2010), editor of Interactional studies of qualitative research interviews (2019), and has contributed chapters to The SAGE handbook of interview research: The complexity of the craft (2012, 2nd ed.), The SAGE Handbook of Qualitative Data Analysis (2014), and The SAGE Handbook of Data Collection (2018) as well as articles to Qualitative Research, Qualitative Inquiry, and International Journal of Research and Method in Education. 